\title{
A periplasmic, $\alpha$-type carbonic anhydrase from Rhodopseudomonas palustris is essential for bicarbonate uptake
}

\author{
László G. Puskás,† Masayuki Inui, Kenneth Zahn and Hideaki Yukawa
}

Author for correspondence: Hideaki Yukawa. Tel: +81774 75 2308. Fax: +81774 752321.

e-mail: yukawa@rite.or.jp

Research Institute of Innovative Technology for the Earth (RITE), 9-2 Kizugawadai, Kizu, Soraku, Kyoto 619-0292, Japan

\begin{abstract}
Intact cells of the purple non-sulfur bacterium Rhodopseudomonas palustris growing anaerobically, but not aerobically, contain carbonic anhydrase (CA) activity. The native enzyme was purified $>2000$-fold to apparent homogeneity and found to be a dimer with an estimated molecular mass of $54 \mathrm{kDa}$ and a subunit molecular mass of $27 \mathrm{kDa}$. The CA gene (acaP) was cloned and its sequence revealed that it was homologous to $\alpha$-type CAs. The upstream region of acaP was fused to the lacz gene and $\beta$-galactosidase activity was measured under different growth conditions. Acetazolamide inhibited purified CA with an $\mathrm{IC}_{50}$ in the range of $10^{-8} \mathrm{M}$, and in the culture media concentrations as low as $30 \mu \mathrm{M}$ inhibited phototrophic growth under anaerobic, light conditions when bicarbonate was used. An acaP:: Kanr mutant strain was constructed by insertion of a kanamycin-resistance cassette and showed a growth pattern similar to wild-type cells grown in the presence of $\mathrm{CA}$ inhibitor. $\mathrm{CO}_{2}$ gas supplied as an inorganic carbon source reversed the effect of mutation or acetazolamide. CA activity measurements, fusion and Western blot experiments confirmed that $\mathrm{CA}$ is expressed under different anaerobic conditions independently of bicarbonate or $\mathrm{CO}_{2}$ and that there is no expression under aerobic conditions.
\end{abstract}

Keywords: carbonic anhydrase, inorganic carbon uptake, Rhodopsendomonas palustris, periplasmic enzyme

\section{INTRODUCTION}

Carbonic anhydrase (CA; EC 4.2.1.1) is a zinccontaining metalloenzyme catalysing the reversible hydration of $\mathrm{CO}_{2}$. CA is important in biological systems because the uncatalysed interconversion between $\mathrm{CO}_{2}$ and $\mathrm{HCO}_{3}^{-}$is slow around neutral $\mathrm{pH}$. Its high efficiency catalysis is fundamental to many biological processes, such as photosynthesis, respiration, $\mathrm{pH}$ homeostasis and ion transport (Badger \& Price, 1992; Tashian, 1989; Vandenberg et al., 1996). Presently, three distinct classes of CAs are recognized based on amino acid sequence comparisons (Hewett-Emmett \& Tashian,

†Present address: Biological Research Center, Hungarian Academy of Sciences, DNA-Chip Laboratory, Szeged, PO Box 521, H-6701, Hungary.

Abbreviations: $A Z$, acetazolamide; $C A$, carbonic anhydrase; $C_{i}$, inorganic carbon; PNSB, purple non-sulfur bacterium; RubisCo, ribulosebisphosphate carboxylase-oxygenase.

The GenBank accession number for the sequence reported in this paper is AB022175.
1996). Among these gene families, significant sequence homologies cannot be recognized. CA has been described in photosynthetic organisms, including higher plants, micro- and macroalgae, and cyanobacteria (Burnell et al., 1990; Fukuzawa et al., 1992; Hatch \& Burnell, 1990; Kimpel et al., 1983; Price et al., 1992). Some photosynthetic organisms have multiple types of CA enzyme found in different cellular locations that serve different functions in the photosynthetic process. In cyanobacteria and algae, different types of CA have been found. The role of extracellular CA is to improve the efficiency of inorganic carbon $\left(\mathrm{C}_{\mathrm{i}}\right)$ transport and it is located in the periplasm or in the cell membrane (Price et al., 1992). The function of the intracellular CA in these organisms is to convert $\mathrm{HCO}_{3}^{-}$to $\mathrm{CO}_{2}$ for fixation by ribulose-bisphosphate carboxylase-oxygenase (RubisCo) (McKay et al., 1993; Rawat \& Moroney, 1995). In plants, intracellular CA enhances the rate of $\mathrm{CO}_{2}$ to $\mathrm{HCO}_{3}^{-}$conversion, for fixation by phosphoenolpyruvate carboxylase (Hatch \& Burnell, 1990). CA has been proposed to be involved in $\mathrm{C}_{i}$ utilization in 
most anaerobic bacteria and archaea (Alber \& Ferry, 1994; Kaplan et al., 1991). CA function in processes other than $\mathrm{C}_{\mathrm{i}}$ utilization has also been verified in several bacteria. In Escherichia coli the cynT gene, encoding $\mathrm{CA}$, is part of the cyanate degradation operon. Its physiological role is to prevent depletion of cellular $\mathrm{HCO}_{3}^{-}$during cyanate decomposition due to loss of $\mathrm{CO}_{2}$ (Guilloton et al., 1992). In acetogenic bacteria the function of CA might be to participate in increasing the intracellular $\mathrm{CO}_{2}$ concentration and to regulate intracellular $\mathrm{pH}$ during acetate production (Braus-Stromeyer et al., 1997).

Purple non-sulfur bacteria (PNSB) can grow either heterotrophically under aerobic conditions or phototrophically under anaerobic light conditions using bicarbonate or $\mathrm{CO}_{2}$ as $\mathrm{C}_{\mathrm{i}}$ source and hydrogen or organic compounds as electron donors (Imhoff, 1995). They exhibit remarkable versatility in aromatic compound transformations and their use as biocatalysts for bioremediation has been suggested (Harwood \& Gibson, 1988). Recently, the use of PNSB for waste treatment and subsequent fixation of $\mathrm{CO}_{2}$ released during industrial processes was proposed (Brenner et al., 1998). Little information exists with regard to the mechanism of $\mathrm{CO}_{2}$ utilization in these bacteria, and their $\mathrm{C}_{\mathrm{i}}$ uptake mechanism is unexplored. Because CA is known to play an important role in $\mathrm{C}_{\mathrm{i}}$ transport and in photosynthetic processes in other organisms, in the present study we intended to verify the presence and the possible function of this enzyme in PNSB. Intracellular, but not periplasmic, CA has been detected in Rhodospirillum rubrum (Gill et al., 1984); however, the biological function of this enzyme was not investigated.

Here we report the identification of a periplasmic, $\alpha$ type CA from Rhodopsendomonas palustris. This is the only type found in animals, but it can also be found in the periplasm and the thylakoid membranes of the eukaryotic unicellular green alga Chlamydomonas reinhardtii (Coleman et al., 1984; Karlsson et al., 1998) and in the eubacterium Neisseria gonorrhoeae (Chirica et al., 1997). In the PNSB Rhodobacter sphaeroides, Rhodobacter capsulatus and Rsp. rubrum $\beta$ - and $\gamma$-type, but not $\alpha$-type, CAs have been detected by immunoblotting with polyclonal antisera and based on sequence searches of the incomplete genome sequences (Smith et al., 1999). We describe the cloning of CA gene, designated acaP, encoding CA protein (AcaP) in Rps. palustris.

\section{METHODS}

Cultivation of bacteria. Rps. palustris No. 7, Rba.sphaeroides and Rsp. rubrum were cultivated at $30^{\circ} \mathrm{C}$ in a minimal medium (Fujii et al., 1983) containing $5 \mathrm{mM}$ 1-propanol and $20 \mathrm{mM} \mathrm{NaHCO}_{3}(\mathrm{pH} 7 \cdot 5)$ under anaerobic conditions using a light incubator when the activity of the strains were compared, when the effect of different concentrations of acetazolamide (AZ; Sigma) was determined and for purification of CA from Rps. palustris No. 7. When comparing CA activities using different organic compounds, the same minimal media was used but instead of 1-propanol, $2 \mathrm{mM}$ hexanoic acid or butylamine was added. When comparing CA activities in different $C_{i}$ concentrations, $1,5,10$ and $20 \mathrm{mM}$ sodium bicarbonate and $2 \mathrm{mM}$ 1-propanol was used in minimal media ( $\mathrm{pH} 7 \cdot 5)$. When the effect of $\mathrm{CO}_{2}$ was studied instead of $\mathrm{NaHCO}_{3}, \mathrm{CO}_{2}$ was bubbled into the media $\left(3 \% \mathrm{CO}_{2}\right.$ in argon). Photoautotrophic growth was studied by growing cells on agar plates anaerobically using $\mathrm{CO}_{2}$ and $\mathrm{H}_{2}$ gas. Comparison of growth of mutant and wild-type cells was also performed on Petri plates set in a small chamber and filled with $\mathrm{CO}_{2}$ with or without $\mathrm{H}_{2}$ at the concentration mentioned above. Aerobic cultivation was performed in van Niel medium (van Niel, 1944) containing $5 \mathrm{mM}$ 1-propanol on a rotary shaker (150 r.p.m.) with or without $20 \mathrm{mM}$ sodium bicarbonate. Fermentative growth of cells was carried out anaerobically in the dark using van Niels minimal medium with $4 \mathrm{mM}$ pyruvate on agar plates.

Sample preparation and enzyme assays. Cells were collected by centrifugation, washed and suspended in $50 \mathrm{mM}$ sodium phosphate buffer ( $\mathrm{pH} 7 \cdot 2$ ) containing $1 \mathrm{mM}$ zinc sulfate. For measurement of CA of intact cells, $200 \mathrm{ml}$ of this suspension $\left(15 \mathrm{OD}_{660} \mathrm{U} \mathrm{ml}^{-1}\right.$ ) was used directly. Cells were treated to obtain the periplasmic and cytoplasmic fractions as previously published (Brandner et al., 1989; Tai \& Kaplan, 1985). For total-cell CA activity and for purification of CA from $R p s$. palustris No. 7 , cell suspension $\left(0.4 \mathrm{~g}\right.$ wet weight $\left.\mathrm{ml}^{-1}\right)$ was passed through a French pressure cell (20000 p.s.i.; $138 \mathrm{MPa}$ ) in the presence of DNase I. The cell debris was centrifuged at 16000 r.p.m. for $20 \mathrm{~min}$ at $4{ }^{\circ} \mathrm{C}$ and the supernatant was used.

$\mathrm{CA}$ activity was measured from the $\mathrm{pH}$ decrease after the addition of $1 \mathrm{ml} \mathrm{CO}$-saturated water to $20 \mathrm{mM}$ Veronal buffer ( $\mathrm{pH} 8 \cdot 5$ ) (Wako Chemicals) containing the test material in a total volume of $2.8 \mathrm{ml}$. Units of enzyme activity $(\mathrm{U})$ were calculated using the equation $\mathrm{U}=\left(t_{0}-t\right) / t$, where $t$ and $t_{0}$ represent the time for a $\mathrm{pH}$ change from 8.5 to 7.0 with and without sample (Wilbur \& Anderson, 1948). Protein concentrations were determined colorimetrically by the method of Bradford (1976) using Bio-Rad dye reagents and standards. $\beta$ Galactosidase activity was determined by measuring the initial rate of hydrolysis of ONPG (Malamy \& Horecker, 1964). Cytochrome $c_{2}$ levels were determined by measuring the difference in the $A_{550}$ between the fully reduced and oxidized forms (Brandner et al., 1989).

Enzyme purification and $\mathrm{N}$-terminal amino acid sequence determination. Cells from 21 total culture volume were collected and disrupted with a French press. Centrifugation of the cell extract was then performed for $20 \mathrm{~min}$ at $16000 \mathrm{~g}$. About $90 \%$ of the total CA activity was obtained in the supernatant fraction. Ammonium sulfate was added to the

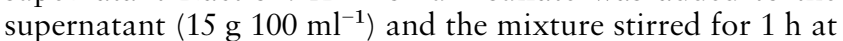
$4{ }^{\circ} \mathrm{C}$. After centrifugation for $20 \mathrm{~min}$ at $16000 \mathrm{~g}$, the same amount of ammonium sulfate was added and the extract treated as above. The precipitate was collected by centrifugation, dissolved in sodium phosphate buffer $(50 \mathrm{mM}, \mathrm{pH}$ $7 \cdot 2$ containing $1 \mathrm{mM}$ zinc sulfate) and stored on ice for $2 \mathrm{~h}$. The mixture was loaded onto a $p$-aminomethylbenzenesulfonamide-agarose (Sigma) ( $3 \mathrm{ml}$ bed volume) column equilibrated with the same buffer. The column was washed with buffer $(20 \mathrm{ml})$, buffer containing $0.7 \mathrm{M} \mathrm{NaCl}(30 \mathrm{ml})$ and $0 \cdot 3 \mathrm{M}$ sodium azide in the same buffer $(30 \mathrm{ml})$. CA activity was eluted with $0.6 \mathrm{M}$ sodium azide. The eluate was concentrated using a $50 \mathrm{kDa}$ cut-off Amicon column. The concentrated eluate was diluted with phosphate buffer, reconcentrated with the same column and rediluted. The diluted enzyme solution was loaded onto Q-Sepharose (Pharmacia) and the flowthrough was collected. This step was repeated using a cationexchange column, CM-Sepharose (Pharmacia). Under various 
$\mathrm{pH}$ conditions CA activity would not bind to anion or cation exchange resins. Although CA could not bind to these columns, collections of the flow-through served to purify CA an additional 1.2-fold. Ammonium sulfate was added to $1.7 \mathrm{M}$ and the sample was loaded onto a Phenyl-Sepharose (Pharmacia) column equilibrated with phosphate buffer (50 mM, pH 7.2) containing 1.7 M ammonium sulfate. After a $50 \mathrm{ml}$ washing step (in the same buffer as used in equilibration), the activity was eluted with $1.6 \mathrm{M}$ ammonium sulfate solution. The fractions containing CA activities were dialysed against phosphate buffer and concentrated as described in the affinity chromatography step.

After purification, $8 \mu \mathrm{g}$ CA enzyme was transferred onto a nitrocellulose membrane (Millipore) and the N-terminal sequence of the protein was determined commercially by the automated Edman degradation procedure (Takara).

Immunoblot analysis of Rps. palustris CA. The soluble cell fractions were analysed by immunoblotting for CA content after separating the proteins on polyacrylamide gels under denaturing (using SDS) or native conditions. Proteins were electrophoretically transferred to nitrocellulose (Millipore). Immunoblotting was performed with mouse antiserum against purified CA and goat anti-mouse antibody-alkaline phosphates conjugate as a detection method, as described previously (Blake et al., 1984).

Cloning and nucleotide sequence determination of acaP. Based on the amino acid sequence of the $\mathrm{N}$ terminus of CA from Rps. palustris (AEGAYHW) the following degenerate primer was synthesized: acap1, 5'-GC(CG)GA(AG)GG(CT)GC(CG)TGGGG-3'. The second primer for PCR was designed according to the highly conserved amino acid motif GSLTTPP among $\alpha$-type CAs: acap2, 5'-CGGCGG(CG)GT(CG)GT(CG)AG(CG)GA(CG)CC-3'. PCR was carried out in a total volume of $100 \mu \mathrm{l}$ with $10 \mathrm{ng}$ Rps. palustris genomic DNA, $0.2 \mathrm{mM}$ dNTPs, $2 \%$ DMSO and $1 \times$ Taq polymerase buffer with $\mathrm{MgCl}_{2}$ and $4 \mathrm{U}$ Taq DNA polymerase (Takara) for 30 cycles at temperatures of $95^{\circ} \mathrm{C}$ for denaturation $(1 \mathrm{~min}), 57^{\circ} \mathrm{C}$ for annealing $(1 \mathrm{~min})$ and $72{ }^{\circ} \mathrm{C}$ for extension $(1 \mathrm{~min})$. After agarose gel electrophoresis of the PCR mixture, the desired fragment (516 nt long) was purified with a PCR purification kit (Pharmacia) and cloned into the pGEMT vector (Promega) and sequenced by the dye-terminator method using ABI reagents and protocol (Perkin Elmer). Using the same primers and PCR conditions, a fulllength genomic clone was identified using PCR from a NaeI genomic library of Rps. palustris DNA in the pBluescript SK(II) vector (Stratagene) by screening serial dilutions of pooled plasmids as template. The nucleotide sequence of the whole NaeI fragment was determined as described below. The nucleotide sequence and the 255 aa ORF encoding $R p s$. palustris CA, designated acaP, is available in the GenBank nucleotide sequence database with the accession number AB022175.

Construction of acaP mutant strain. A kanamycin-resistance gene cassette was excised from vector pUC4K (Pharmacia) by PstI restriction enzyme cleavage and gel purification, and inserted into the PstI site within the coding region of acaP (into the 225th nt position). The recombinant fragment was amplified with two specific primers complementary to regions flanking the genomic NaeI sites, which also contained BamHI sites at their $5^{\prime}$ ends. The resulting fragment was digested with BamHI and cloned into the pGP-704 vector that had been digested with BglII. Procedures used to obtain the Rps. palustris double crossover acaP : : kanR insertion mutant strain were as described by Inui et al. (1999).
Construction of acaP-lacZ fusion vector. The coding region of the lacZ gene was excised from the plasmid pMC1871 (Pharmacia) with PstI/Bam HI and cloned into the pBluescript SK (II) multicloning site resulting in the plasmid pBlac. A $500 \mathrm{bp}$ upstream region of acaP (from the first Ala codon of the mature CA enzyme) was amplified with primers having EcoRI and PstI sites, cut with the same enzymes and cloned into pBlac upstream of the lacZ gene. The EcoRI-BamHI fragment was cut out and cloned into the corresponding sites of pMG103 to produce plasmid pMlaca. pMlaca was electroporated into Rps. palustris cells or transformed into E. coli cells and the transformants were selected with kanamycin and used in $\beta$-galactosidase fusion studies.

DNA sequencing. DNA sequencing was performed using Thermo Sequenase dye-terminators and samples were run on an ABI 373 fluorescent sequencer. All plasmid inserts produced by PCR in this study were confirmed by sequencing.

Materials. All chemicals were purchased from Wako Chemicals unless otherwise mentioned. Goat anti-mouse antibody-alkaline phosphatase conjugate was purchased from Boehringer Mannheim Biochemicals. Restriction endonucleases were obtained from Takara Biochemicals and were used according to the manufacturer's specifications.

\section{RESULTS}

\section{CA activity in Rps. palustris cells}

Protein preparations of Rps. palustris cells cultivated under anaerobic conditions exhibited total CA activities from total cell protein [2.95-3.20 U (mg protein $\left.)^{-1}\right]$, similar to those of other CA-containing bacteria (Alber \& Ferry, 1994; Braus-Stromeyer et al., 1997), whereas cells grown aerobically showed little or no activity $(<0 \cdot 1 \mathrm{U})$ (Table 1$)$. Intact cells showed CA activity

\section{Table 1. CA activities of Rps. palustris}

Activities of cell extracts cultivated under different growth conditions and substrates. Activity is expressed as $\mathrm{U}(\mathrm{mg}$ protein $)^{-1}$.

\begin{tabular}{lc} 
Condition & Activity \\
\hline $\begin{array}{l}\text { Anaerobic conditions } \\
\text { Photoheterotrophic light (minimal medium) }\end{array}$ \\
$\quad$ Ethanol + bicarbonate & $3 \cdot 05$ \\
1-Propionate + bicarbonate & $3 \cdot 20$ \\
1-Butylamine + bicarbonate & $3 \cdot 02$ \\
$\quad$ Ethanol $+\mathrm{CO}_{2}$ & $3 \cdot 08$ \\
Photoautotrophic light (minimal medium) & \\
$\quad \mathrm{CO}_{2}+\mathrm{H}_{2}$ & $2 \cdot 98$ \\
Fermentative dark (rich medium) & \\
$\quad$ Pyruvate & $2 \cdot 95$ \\
Aerobic conditions & \\
Heterotrophic dark (rich medium) & \\
$\quad$ Ethanol + bicarbonate & $0 \cdot 05$ \\
$\quad$ Ethanol - bicarbonate & $0 \cdot 07$ \\
1-Butylamine & $0 \cdot 03$ \\
$\quad$ Ethanol (minimal medium) & $0 \cdot 07$ \\
Pyruvate (rich medium) & $0 \cdot 08$
\end{tabular}


Table 2. Purification of CA from Rps. palustris

\begin{tabular}{|c|c|c|c|c|c|c|}
\hline Purification step & $\begin{array}{l}\text { Volume } \\
\qquad(\mathrm{ml})\end{array}$ & $\begin{array}{l}\text { Protein } \\
\quad(\mathrm{mg})\end{array}$ & $\begin{array}{c}\text { Total } \\
\text { activity } \\
(\mathbf{U})\end{array}$ & $\begin{array}{l}\text { Specific } \\
\text { activity } \\
\left(\mathbf{U} \mathbf{~ m g}^{-1}\right)\end{array}$ & $\begin{array}{c}\text { Recovery } \\
(\%)\end{array}$ & $\begin{array}{l}\text { Purification } \\
\quad \text { (fold) }\end{array}$ \\
\hline Total cell extract & 100 & 1575 & 4798 & $3 \cdot 05$ & 100 & $1 \cdot 0$ \\
\hline Soluble fraction & 98 & 1160 & 3980 & $3 \cdot 43$ & 83 & $1 \cdot 1$ \\
\hline $\begin{array}{l}\text { Ammonium sulfate } \\
\text { fraction }\end{array}$ & 80 & 710 & 3360 & $4 \cdot 73$ & 70 & $1 \cdot 6$ \\
\hline Affinity column & 15 & $1 \cdot 5$ & 2845 & $1896 \cdot 7$ & 59 & $621 \cdot 9$ \\
\hline Ion-exchange column & 20 & $1 \cdot 03$ & 2342 & $2276 \cdot 7$ & 49 & $746 \cdot 5$ \\
\hline $\begin{array}{l}\text { Phenyl-Sepharose } \\
\text { column }\end{array}$ & 15 & $0 \cdot 29$ & 1818 & $6269 \cdot 0$ & 38 & $2055 \cdot 4$ \\
\hline
\end{tabular}

$\left[0.6 \mathrm{U}\left(\mathrm{OD}_{600} \mathrm{U} \text { bacteria }\right)^{-1}\right]$ due to periplasmic or membrane-bound CA enzyme. Activity was measured from cells that were cultivated under different anaerobic conditions: fermentative dark conditions using pyruvate as carbon source, photoheterotrophic light conditions using different organic compounds and $\mathrm{CO}_{2}$ or bicarbonate as the $\mathrm{C}_{\mathrm{i}}$ source, photoautotrophic light condition using $\mathrm{H}_{2}$ and $\mathrm{CO}_{2}$. Cells that were cultivated under aerobic heterotrophic conditions with or without bicarbonate in the media showed no activity. This result did not depend on the applied organic carbon source (Table 1).

\section{Enzyme purification}

Under a variety of conditions, CA did not bind to cationor anion-exchange columns. However, these steps were useful to remove certain contaminants. Major purification was achieved with affinity chromatography. Strong binding of the enzyme to the $p$-aminomethylbenzenesulfonamide-agarose column was observed and this is consistent with the high affinity of CA for AZ. The enzyme was purified more than 2000-fold, with an overall recovery of $38 \%$ (Table 2 ). The specific activity of the purified enzyme $\left(6269 \mathrm{U} \mathrm{mg}^{-1}\right)$ is comparable to that of commercially available human erythrocyte isozyme II (7870 $\mathrm{U} \mathrm{mg}^{-1}$ ).

\section{Properties of the purified enzyme}

The enzyme appeared as a single band of about $27 \mathrm{kDa}$ on a $4-20 \%$ gradient SDS polyacrylamide gel after gel electrophoresis and Coomassie brilliant blue staining (Fig. 1a). On a native gel (acrylamide gradient 4-20\%) $\mathrm{CA}$ also gave a single band (Fig. 1b). To examine the presence of CA enzyme in cells cultivated under different conditions and for localization studies, mouse polyclonal antisera were raised against the purified CA from Rps. palustris. As shown in Fig. 2, the antibodies detected a polypeptide of the same size as CA in a Western blot analysis and could detect very small amounts of purified CA protein. When antiserum was (a)

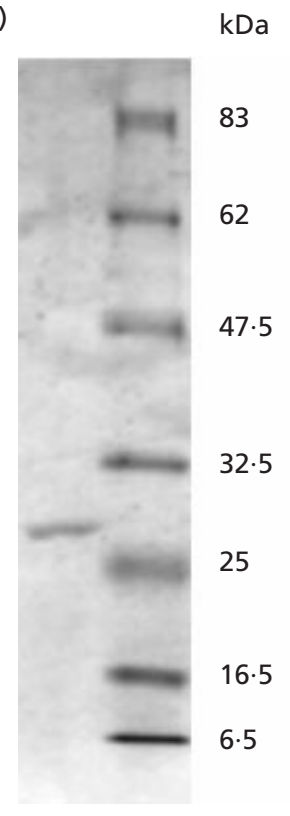

(b)

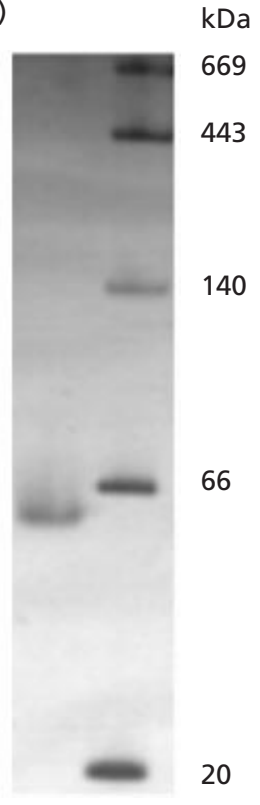

Fig. 1. Denaturing (a) and native (b) PAGE of CA from Rps. palustris. The molecular mass of the markers is indicated. One microgramme protein from the Phenyl-Sepharose chromatography step was applied.

used against whole-cell extracts, no other protein showed reactivity, thus it seems that the antiserum is specific to CA from Rps. palustris.

The migration of the purified enzyme was analysed on a series of denaturing and native gels containing different polyacrylamide concentrations and the apparent size of the enzyme was determined by the method of Ferguson (1964). Under denaturing conditions the estimated molecular mass of CA is about $27 \mathrm{kDa}$ while under native conditions the molecular mass is approximately $54 \mathrm{kDa}$, suggesting that the native enzyme is a dimer. The $\mathrm{NH}_{2}$ terminus of the purified CA protein was determined by the automated Edman degradation pro- 


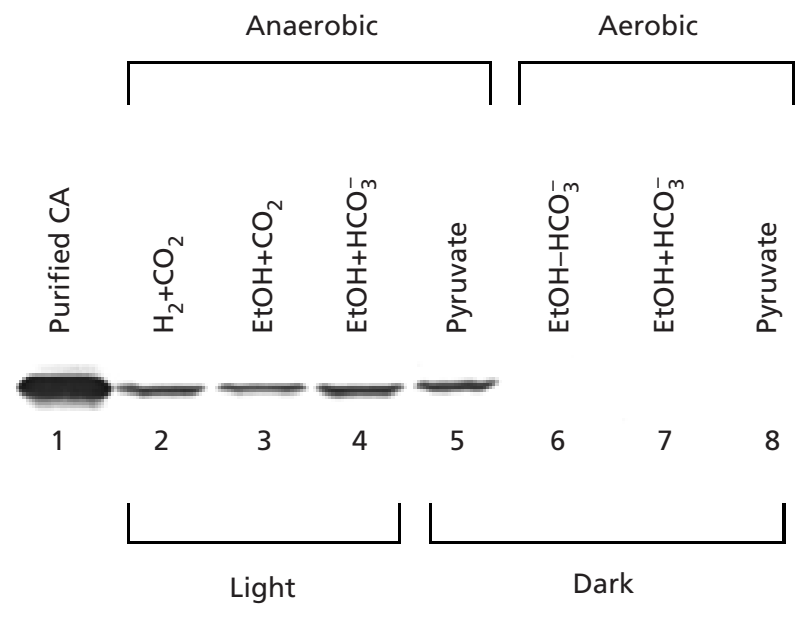

Fig. 2. Immunoblot analysis of protein extracts from Rps. palustris cultivated under different conditions. Lane 1 contains purified CA as a control. Under photoautotrophic (lane 2) and photoheterotrophic (lanes 3 and 4) conditions, cells were cultivated in minimal media at $35^{\circ} \mathrm{C}$ in the light using bicarbonate or $\mathrm{CO}_{2}$ as the $\mathrm{C}_{\mathrm{i}}$ source as indicated. Under fermentative conditions (lane 5) cells were grown in the dark in an anaerobic chamber using pyruvate in rich media at $35^{\circ} \mathrm{C}$. When cells were cultivated under heterotrophic conditions in the presence of oxygen (lanes 6,7 and 8), the same media, and organic and inorganic carbon compounds were used as in the case of the corresponding photoheterotrophic conditions (lanes 3,4 and 5). Aerobic growth in the dark was at $35{ }^{\circ} \mathrm{C}$ with shaking. Blotting was performed with mouse antiserum against purified CA and goat anti-mouse antibody-alkaline phosphatase conjugate as a detection method.

cedure using a band isolated from a native gel. $\mathrm{NH}_{2}$ terminal analysis of the first 12 aa revealed a single homogeneous sequence (AEGAYHWGYEGE), so the CA dimer is probably composed of identical subunits.

We determined the $\mathrm{IC}_{50}$ values (concentration required for $50 \%$ inhibition of activity) of several inhibitors of CA reported from studies in other organisms (Maren \& Sanyal, 1983; Sugrue, 1996) $\left(\mathrm{N}_{3}^{-}, 6.0 \times 10^{-3} \mathrm{M}\right.$; $\mathrm{Cl}^{-}$, $>10^{-2} \mathrm{M}$; AZ, $\left.3 \cdot 1 \times 10^{-8} \mathrm{M}\right)$. AZ was a more effective inhibitor of this CA than of other bacterial CAs (BrausStromeyer et al., 1997; Yu et al., 1992). The values obtained here are more characteristic of human CAs and other CAs from the $\alpha$ family (Armstrong et al., 1966; Lindskog et al., 1971; Price et al., 1992). Monovalent ions were significantly less effective than for some bacterial CAs (Braus-Stromeyer et al., 1997; Yu et al., 1992). The enzyme also has an esterase activity detected with $p$-nitrophenylacetate as the substrate (data not shown).

\section{Cellular localization of CA}

Rps. palustris is a Gram-negative bacterium and contains two cellular compartments, the cytoplasm and the periplasm. CA activity was found only in the periplasmic space (the cytoplasmic fraction exhibited $0.49 \mathrm{U}$, while the periplasmic fraction showed $11.5 \mathrm{U}$ ). The purity of the periplasmic extract was evaluated by using marker enzymes with known localizations. We chose cytochrome $c_{2}$ as the periplasmic, and $\beta$-galactosidase as the cytoplasmic marker. Fractionation and measurements of marker enzyme activities were performed as published elsewhere (Brandner et al., 1989; Tai \& Kaplan, 1985). In the cells grown under photosynthetic conditions, cytochrome $c_{2}$ and CA were found only in the periplasmic fraction $(997 \mathrm{pmol}$ Cyt $c$ in the periplasm, and $173 \mathrm{pmol}$ Cyt $c$ in the cytoplasmic fraction), while $\beta$-galactosidase activity appeared only in the cytoplasmic fraction (260 Miller U in the cytoplasm and 38 Miller $U$ in the periplasmic fraction). Since wildtype Rps. palustris No. 7 strain does not show $\beta$ galactosidase activity, we constructed a plasmid which contains the E. coli lacZ gene using an Rps. palustris shuttle vector (Inui et al., 2000). To examine the localization of CA by another method we used immunoblot analysis. We used specific antisera against the purified enzyme and checked the protein fractions from the periplasm and the cytosol. We were able to confirm the periplasmic location of CA as observed with enzymic assays (data not shown).

\section{Cloning and sequence data comparison of CA gene, acaP}

Based on the sequence of the first $12 \mathrm{NH}_{2}$-terminal amino acid residues of the purified CA and from studies of inhibitor specificity, we assumed that Rps. palustris CA belongs to the $\alpha$ class. Two degenerate primers were designed for PCR based on the first $\mathrm{NH}_{2}$-terminal 8 aa and on one internal conserved sequence region present in all $\alpha$-CAs (Hewett-Emmett \& Tashian, 1996) (see Methods). PCR was used to amplify a DNA fragment of $516 \mathrm{bp}$ which was cloned and sequenced. Nucleotide sequence similarity comparisons showed that this fragment had significant homology to other $\alpha$-CAs in the database. To identify an E. coli clone having the fulllength Rps. palustris CA gene, PCR amplification was used to screen a NaeI genomic library from Rps. palustris in pBluescript SK II. A 1443 bp NaeI fragment was found to contain the full-length CA gene. From the DNA sequence and the $\mathrm{NH}_{2}$-terminal amino acid determination we assume that there is a 25 aa signal sequence which is responsible for the periplasmic export of the enzyme. A positively charged part in the amino terminus of the possible signal motif and a following hydrophobic core are recognized characteristics of bacterial signal peptides (von Heijne, 1984). The 18 residue hydrophobic region ends in the $+1,-1$ AXA motif characteristic of the recognition site of signal peptidase (Perlman \& Halvorson, 1983). The protein is thus predicted to be made as a $27,302 \mathrm{Da}$ precursor which is cleaved between Ala-25 and Ala-26 to produce a mature 230 residue protein of $24772 \mathrm{Da}$. The putative initiation codon (ATG) is preceded by a possible ribosome-binding site sequence (GGAGA), $5 \mathrm{nt}$ upstream. Downstream from the ORF is a possible rhoindependent transcription terminator. The nucleotide sequence and the ORF, designated acaP, encodes the 255 aa Rps. palustris CA. The deduced amino acid 

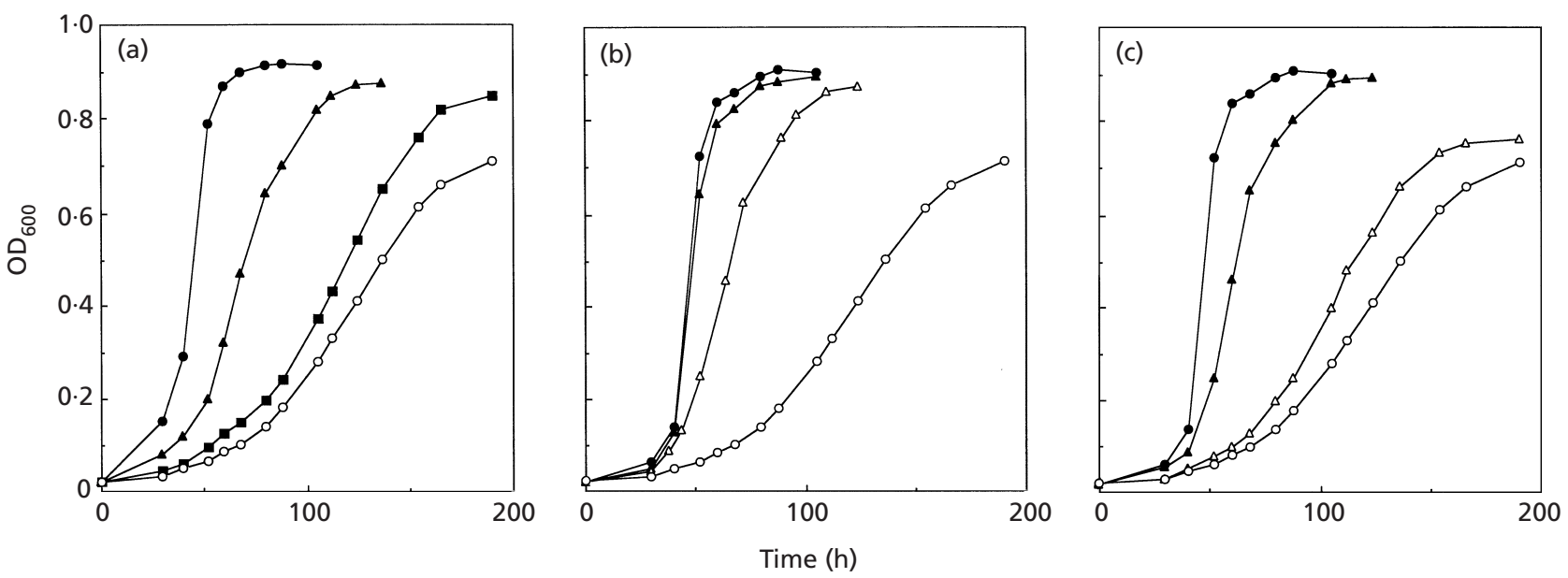

Fig. 3. (a) Effects of different concentrations of $A Z$ on photoheterotrophic growth of wild-type Rps. palustris cells. Without AZ, 0; with $60 \mu \mathrm{M} \mathrm{AZ}, \boldsymbol{\square} ; 30 \mu \mathrm{M} \mathrm{AZ}, \boldsymbol{\Delta}$. The growth pattern of the acaP mutant $(O)$ without the inhibitor under the same conditions using bicarbonate as the $C_{i}$ source and ethanol as the organic carbon compound is also shown. Cells were incubated at $35^{\circ} \mathrm{C}$ in the light in minimal medium. (b) Photoheterotrophic growth of the wild-type ( $\boldsymbol{\Delta}$ ) and mutant $(\triangle)$ cells in the presence of $\mathrm{CO}_{2}$ and of the wild-type $(0)$ and mutant cells $(O)$ in the presence of bicarbonate. (c) The effects of $\mathrm{pH}$ on photoheterotrophic growth; wild-type $(\mathbf{O})$ and mutant cells $(\bigcirc)$ at $\mathrm{pH} 7$; wild-type $(\boldsymbol{\Delta})$ and mutant cells $(\triangle)$ at $\mathrm{pH} 6$ using the same conditions as in (a).

sequence of acaP was aligned with the sequences of CA from Anabaena, Synechococcus, Erwinia carotovora, Klebsiella pneumoniae, N. gonorrhoeae and human CA isozymes I and II. Rps. palustris CA showed the highest homology to bacterial CAs $(35 \cdot 7-45 \cdot 7 \%$ identities). Comparing Rps. palustris CA with the two human CA isozymes I and II, the identities were $33 \%$ and $34.6 \%$, respectively. The highest identity was found with the $\beta$ Proteobacterium Neisseria $(42.9 \%)$ and the $\gamma$-Proteobacteria Erwinia (45.7\%) and Klebsiella (42.9\%).

\section{Regulation of acaP expression}

CA activity was measured and was the same when cells were grown under different anaerobic conditions: photoheterotrophic light, photoautotrophic light or fermentative dark conditions. In the presence of oxygen, CA activity could not be detected using the media listed in Table 1. The presence of a CA band as demonstrated by immunoblot analysis under each condition (Fig. 2) was in agreement with the activity data. The enzyme was detected under different anaerobic conditions. No difference was detected in the amount of CA enzyme in cells grown in low and high concentrations of bicarbonate under different anaerobic conditions (data not shown).

To investigate the transcriptional regulation of acaP, an acaP::lacZ fusion was constructed. The non-coding, upstream region with the proposed translation initiation signals of acaP was fused translationally in-frame to the first codon of lacZ. In E. coli the $\beta$-galactosidase activity remained unchanged when cells were shifted from aerobic to anaerobic conditions, while a dramatic change was observed in the case of Rps. palustris, where activity was more than 20-fold higher when cells were incubated in the absence of oxygen $(0.9$ compared to 19.7 Miller U). Expression of $\beta$-galactosidase occurred within several hours and cells plated in the presence of X-Gal became blue when examined on LB plates containing the indicator. In E. coli the expression of acaP gene seemed to be constitutive compared to expression from the native lac promoter, and the strength of the acaP promoter was approximately 13fold weaker than the lac promoter both in E. coli and in $R p s$. palustris. The immunoblotting and $\beta$-galactosidase fusion studies suggest that CA expression is regulated at the transcriptional level.

\section{Inhibition of phototrophic growth by CA inhibitors}

Since AZ was an effective in vitro inhibitor of CA, we studied the effect of AZ on the growth of Rps. palustris under anaerobic light conditions. Preliminary studies showed that CA activity could be completely inhibited in intact cells using $0 \cdot 2 \mathrm{mM}$ AZ. Lower concentrations of AZ inhibited photosynthetic growth in a concentration-dependent manner when bicarbonate was used as the $C_{i}$ source (Fig. 3a). Even higher concentrations of $A Z$ than these had no effect on aerobic growth (data not shown). These results are in good agreement with the observation that extracts from cells harvested under aerobic conditions exhibited no CA activity. Cells showed CA activity when grown under photoautotrophic and fermentative conditions. When $\mathrm{CO}_{2}$ was used instead of bicarbonate under photoheterotrophic conditions, AZ had no inhibitory effect on growth (data not shown). 


\section{Insertion mutation of acaP and characterization of the mutant strain}

To obtain more information regarding the physiological role of CA, we made a mutant strain of $R p$ s. palustris by insertion of a kanamycin-resistance cassette into the coding region of acaP. The single-crossover mutants showed resistance to another antibiotic, gentamicin, while strains that displayed only kanamycin resistance were double-crossover mutants and these were selected for further analysis. The homologous recombination event was confirmed by PCR and Southern blotting (data not shown). The mutant strain showed a similar growth pattern to wild-type cells cultivated in the presence of $60 \mu \mathrm{M} \mathrm{AZ}$ in minimal medium containing bicarbonate as the $C_{i}$ source (Fig. 3a). Phototrophic growth was inhibited for several days when bicarbonate was used. The very slow growth can be explained by the slow conversion of bicarbonate to $\mathrm{CO}_{2}$ without catalysis at close-to-neutral $\mathrm{pH}$ in liquid media. Using $\mathrm{CO}_{2}$ with different organic compounds or with $\mathrm{H}_{2}$, no difference in growth was observed between the wild-type and the mutant cells using solid media in small anaerobic chambers (data not shown).

\section{Effect of $\mathrm{CO}_{2}$ and $\mathrm{pH}$ on acaP mutant and wild-type cells}

When cell growth was arrested by AZ under phototrophic conditions using bicarbonate, the inhibitory effect could be diminished by bubbling $\mathrm{CO}_{2}$ gas into the media (data not shown). An acaP mutant strain could also grow when the media was supplemented with $\mathrm{CO}_{2}$ (Fig. 3b). The same effect could be seen when the $\mathrm{pH}$ of the media was lowered with buffers. Although wild-type cells grew more slowly in lower $\mathrm{pH}(\mathrm{pH} 5-6)$ media, mutant bacteria showed increased growth, probably due to the increased $\mathrm{CO}_{2}$ conversion from bicarbonate (Fig. $3 c)$.

\section{DISCUSSION}

One report on CA from the PNSB has so far appeared where a cytoplasmic CA from Rsp. rubrum was purified and some features of the enzyme were studied (Gill et al., 1984). The physiological role of this enzyme was not studied, nor was a periplasmic location established. In this report, CA from Rps. palustris is studied in detail. We have found that intact cells exhibit CA activity when cultivated under photosynthetic growth conditions. Enzyme activity could be localized mainly to the periplasmic space and this was confirmed by using cytochrome $c_{2}$ and $\beta$-galactosidase enzymes as control markers localized to the periplasm and cytoplasm, respectively. CA activity was unchanged when cells were grown under different anaerobic conditions: photoheterotrophic light, photoautotrophic light or fermentative dark conditions. Under photoheterotrophic conditions, the levels of CA are not regulated in response to the growth substrate, and enzymic activities are similar in alcohol, organic acid or alkylamine-grown cells. No correlation was established between CA activity and the concentration of $\mathrm{C}_{\mathrm{i}}$ in the media. Little $[<0 \cdot 1 \mathrm{U}(\mathrm{mg}$ protein $)^{-1}$ ] or no activity was detected when cells were cultured under aerobic conditions.

\section{CA protein structural relationships}

Cloning of the acaP gene and determination of the amino acid sequence demonstrates that Rps. palustris CA is homologous to $\alpha$-type CAs. Stronger homology and other distinctive features characteristic of bacterial CAs of the same family were recognized, which suggest a common molecular structure and also a role in the localization of the enzyme. The $\mathrm{NH}_{2}$ terminus of all bacterial CAs contains a possible signal sequence and the AXA signal peptidase recognition motif can be seen in all of the cases except in the Klebsiella enzyme. Four distinct deletions in the sequence can be seen when compared to human CA isozymes I and II (data not shown). Three of them are located in the regions that connect $\beta$ strands $\mathrm{D}, \mathrm{E}$ and $\mathrm{F}$, which are central characteristics of the dominating structural element, the 10 -stranded $\beta$ sheet of all $\alpha$-CAs (Eriksson et al., 1988). A fourth gap is located close to the $\mathrm{C}$ terminus and might result in a shorter corner loop which is longer in the human isoenzymes molecular periphery region (Eriksson et al., 1988). Thirty-six amino acids are found to be highly conserved among all $\alpha$-CAs. Three histidines (His-94, His-96, His-119), which are the three zinc ligands in the enzyme, as well as other conserved amino acids (Gln-92, Glu-117, Ala/Val-121, Val-143) are unchanged. Interestingly, there are two positions where all bacterial CAs have cysteine residues (Cys-53 and Cys200 ; Rps. palustris numbering) while human isozymes have alanine and leucine in those positions. In the case of the newly discovered $\alpha$-type CA from the thylakoid membrane of C. reinhardtii, cysteines are also found in these positions (Karlsson et al., 1998); this may suggest a close evolutionary relationship to bacterial CAs.

\section{Localization and expression of CA}

$\mathrm{CA}$ and RubisCo are associated in the carboxysomes of cyanobacteria and possibly in the pyrenoids of algae (Price et al., 1992). The carboxysomes are postulated to contain a specialized CA at the active site to provide $\mathrm{CO}_{2}$. It is also possible that intracellular CA aids in the conversion of $\mathrm{CO}_{2}$ to $\mathrm{HCO}_{3}^{-}$for fixation by phosphoenolpyruvate carboxylase (Hatch \& Burnell, 1990). Both biochemical pathways are found in photosynthetic bacteria (Buchanan et al., 1967; Inui et al., 1997; Tabita, 1995) although carboxysomes are not found in PNSB and our results suggest that CA enzyme is not associated with RubisCo, because the main CA activity was found in the periplasmic fraction.

Periplasmic localization and the presence of the enzyme only under anaerobic conditions suggests that CA participates in $\mathrm{C}_{\mathrm{i}}$ utilization in this bacterium. We also tested two other PNSB, Rba. sphaeroides and Rsp. rubrum, and found the same phenomenon (data not shown). This suggests that an $\alpha$-type CA exists in these PNSB as well. We cannot exclude the presence of other 
intracellular accumulation systems for $\mathrm{C}_{\mathrm{i}}$, because when different $\mathrm{C}_{\mathrm{i}}$ concentrations were used under phototrophic conditions, the expression and activity of the CA studied here did not change. Other $\mathrm{C}_{\mathrm{i}}$ transport proteins probably act under phototrophic conditions, either in cooperation with CA or independently. These aspects of the uptake mechanism await clarification.

Anaerobic induction and transcriptional regulation of the acaP gene is suggested by the analysis of the acaP : : lacZ fusion. A 20 -fold change in $\beta$-galactosidase activity was observed in the case of Rps. palustris, when cells were incubated anaerobically. Induction occurred within several hours and was also detected on plates where the cells became blue in the presence of X-Gal. In E. coli, the $\beta$-galactosidase activity remained unchanged when cells were shifted from aerobic to anaerobic conditions, suggesting that the anaerobic regulation of CA expression is specific for Rps. palustris. In E. coli, $\beta$ galactosidase expression from the acaP-lacZ fusion gene was much weaker than in the case of the full length lacZ gene with its own promoter. These results suggest that the promoter of $a c a P$ is quite weak and may be regulated at the transcriptional level by oxygen via an oxygen-responsive transcriptional regulatory system as found in other bacteria (Monson et al., 1995; Unden \& Schirawski, 1997). However, FixL-like and Fnr-like recognition sequences found in other oxygen regulatory systems could not be discerned. It is also possible that the expression of CA is controlled by a global regulatory system, like the one recognized to control aerobic and anaerobic $\mathrm{CO}_{2}$ metabolism in Rsp. rubrum and Rba. sphaeroides. In these bacteria the RegA/RegB system was found to regulate the aerobic and anaerobic expression of genes encoding enzymes of primary and alternative $\mathrm{CO}_{2}$ fixation and integrates photosynthesis and nitrogen fixation (Qian \& Tabita, 1996; Joshi \& Tabita, 1996). However, a RegA-like consensus recognition motif (Du et al., 1998) was not found in the sequence of $a c a P$, nor upstream of the coding region, which suggests that a different regulatory system is involved.

\section{Physiological role of CA}

In PNSB, CA has an important role under anaerobic growth conditions when bicarbonate is the $C_{i}$ source. Growth inhibition could be detected by inhibiting the extracellular CA of Rps. palustris by the specific CA inhibitor AZ, and a growth defect was observed in the acaP mutant. Growth of wild-type cells in the presence of $\mathrm{AZ}$ or the acaP mutant was slowed by several days but this inhibitory effect could be largely reversed using $\mathrm{CO}_{2}$, or partially reversed when the $\mathrm{pH}$ of the media was lowered and the non-enzymic conversion of bicarbonate to $\mathrm{CO}_{2}$ is much faster. From these results we assume that the cell membrane is a barrier to the bicarbonate ion, but that $\mathrm{CO}_{2}$ can penetrate by diffusion into the cytoplasm. The function of CA in Rps. palustris, and probably in other PNSB, is to accelerate the bicarbonate- $\mathrm{CO}_{2}$ conversion in the periplasmic space. This process might be analogous to CA function in cyanobacteria and algae; however, intact cells of cyanobacteria exhibit very low $\mathrm{CA}$ activity and inactivation of the cyanobacterial ecaA gene, which encodes extracellular CA, did not give a dramatic change in photosynthetic growth (Soltes-Rak et al., 1997). Although there are slight differences in periplasmic CA activities, CA seems to function universally in $C_{i}$ utilization in photosynthetic microorganisms.

We believe that this work contributes to a basic understanding of the key reactions in $\mathrm{C}_{\mathrm{i}}$ utilization and of the nature of anaerobic/aerobic gene regulation in Rps. palustris. We also hope that this knowledge will prove useful in efforts to improve $\mathrm{CO}_{2}$ fixation and photosynthetic ability in this species for a variety of biotechnological applications.

\section{ACKNOWLEDGEMENTS}

We thank H. Yamagata for helpful discussions. This work was supported by the New Energy and Industrial Technology Development Organization (NEDO). L. G. Puskás was supported by a NEDO fellowship.

\section{REFERENCES}

Alber, B. E. \& Ferry, J. G. (1994). A carbonic anhydrase from the archaeon Methanosarcina thermophila. Proc Natl Acad Sci U S A 91, 6909-6913.

Armstrong, J. M., Myers, D. V., Verpoorte, J. A. \& Edsall, J. T. (1966). Purification and properties of human erythrocyte carbonic anhydrases. J Biol Chem 21, 5137-5149.

Badger, M. R. \& Price, G. D. (1992). The $\mathrm{CO}_{2}$ concentrating mechanism in cyanobacteria and green algae. Physiol Plant 84, 606-615.

Blake, M. S., Johnston, K. H., Russel-Jones, G. J. \& Gotschild, E. C. (1984). A rapid, sensitive method for detection of alkaline phosphatase-conjugated anti-antibody on Western blots. Anal Biochem 136, 175-179.

Bradford, M. M. (1976). A rapid and sensitive method for quantitation of microgram quantities of protein utilizing the principle of protein-dye binding. Anal Biochem 72, 248-254.

Brandner, J. P., McEwan, A. G., Kaplan, S. \& Donohue, T. J. (1989). Expression of the Rhodobacter sphaeroides cytochrome c2 structural gene. J Bacteriol 171, 360-368.

Braus-Stromeyer, S. A., Schnappauf, G., Braus, G. H., Gossner, A. S. \& Drake, H. L. (1997). Carbonic anhydrase in Acetobacterium woodii and other acetogenic bacteria. J Bacteriol 179, 7197-7200.

Brenner, V., Inui, M., Nunoura, N., Momma, K. \& Yukawa, H. (1998). Studies on $\mathrm{CO}_{2}$ fixation in PNSB: utilization of waste as the additional source of carbon for $\mathrm{CO}_{2}$ fixation by PNSB. In Advances in Chemical Conversions for Mitigating Carbon Dioxide: Studies in Surface Science and Catalysis, vol. 114, pp. 593-596. Edited by T. Inui, M. Anpo, K. Izui, S. Yanagida \& T. Yamaguchi. Amsterdam: Elsevier.

Buchanan, B. B., Evans, M. C. W. \& Arnon, D. I. (1967). Ferredoxin-dependent carbon assimilation in Rhodospirillum rubrum. Arch Mikrobiol 59, 32-40.

Burnell, J. N., Gibbs, M. J. \& Hatch, M. D. (1990). Spinach chloroplastic carbonic anhydrase: nucleotide sequence analysis of cDNA. Plant Physiol 92, 37-40. 
Chirica, L. C., Elleby, B., Jonsson, B.-H. \& Lindskog, S. (1997). The complete sequence, expression in Escherichia coli, purification and some properties of carbonic anhydrase from Neisseria gonorrhoeae. Eur J Biochem 244, 755-760.

Coleman, J. R., Berry, J. A., Togasaki, R. K. \& Grossman, A. R. (1984). Identification of extracellular carbonic anhydrase of Chlamydomonas reinhardtii. Plant Physiol 76, 472-477.

Du, S., Bird, T. H. \& Bauer, C. E. (1998). DNA binding characteristics of RegA. J Biol Chem 273, 18509-18513.

Eriksson, A. E., Jones, T. A. \& Liljas, T. A. (1988). Refined structure of human carbonic anhydrase II at $2 \AA$ resolution: proteins. Struct Funct Genet 4, 274-282.

Ferguson, K. A. (1964). Starch-gel electrophoresis - application to the classification of pituitary proteins and polypeptides. Metabolism 13, 985-1002.

Fujii, T., Nakazawa, A., Sumi, N., Tani, H., Ando, A. \& Yabuki, M. (1983). Utilization of alcohols by Rhodopseudomonas sp. No. 7 isolated from $n$-propanol-enrichment cultures. Agric Biol Chem 47, 2747-2753.

Fukuzawa, H., Suzuki, E., Komukai, Y. \& Miyachi, S. (1992). A gene homologous to chloroplast carbonic anhydrase (icfA) is essential to photosynthetic carbon dioxide fixation by Synechococcus PCC7942. Proc Natl Acad Sci US A 89, 4437-4441.

Gill, S. R., Fedorka-Cray, P. J., Tweten, R. K. \& Sleeper, B. P. (1984). Purification and properties of the carbonic anhydrase of Rhodospirillum rubrum. Arch Microbiol 138, 113-118.

Guilloton, M. B., Korte, J. J., Lamblin, A. F., Fuchs, J. A. \& Anderson, P. M. (1992). Carbonic anhydrase in Escherichia coli. J Biol Chem 267, 3731-3734.

Harwood, C. S. \& Gibson, J. (1988). Anaerobic and aerobic metabolism of diverse aromatic compounds by the photosynthetic bacterium Rhodopseudomonas palustris. Appl Environ Microbiol 54, 712-717.

Hatch, M. D. \& Burnell, J. N. (1990). Carbonic anhydrase activity in leaves and its role in the first step of $\mathrm{C} 4$ photosynthesis. Plant Physiol 93, 380-383.

von Heijne, G. (1984). How signal sequences maintain cleavage specificity. J Mol Biol 173, 243-251.

Hewett-Emmett, D. \& Tashian, R. E. (1996). Functional diversity, conservation, and convergence in the evolution of the $\alpha, \beta, \gamma$ carbonic anhydrase gene families. Mol Phylogenet Evol 5, 50-77.

Imhoff, J. F. (1995). Taxonomy and physiology of photosynthetic purple bacteria and green sulfur bacteria. In Anoxygenic Photosynthetic Bacteria: Advances in Photosynthesis, pp. 1-15. Edited by R. E. Blankenship, M. T. Madigan \& C. E. Bauer. Dordrecht: Kluwer.

Inui, M., Dumay, V., Zahn, K., Yamagata, H. \& Yukawa, H. (1997). Structural and functional analysis of the phosphoenolpyruvate carboxylase gene of Rhodopseudomonas palustris No. 7. J Bacteriol 179, 4942-4945.

Inui, M., Nakata, K., Roh, J. H., Zahn, K. \& Yukawa, H. (1999). Molecular and functional characterization of the Rhodopseudomonas palustris No. 7 phosphoenolpyruvate carboxykinase gene. J Bacteriol 181, 2689-2696.

Inui, M., Roh, J. H., Zahn, K. \& Yukawa, H. (2000). Structural analysis of the cryptic plasmid pMG101 from Rhodopseudomonas palustris and construction of stable cloning vectors. Appl Environ Microbiol 66, 54-63.

Joshi, H. M. \& Tabita, F. R. (1996). A global two component signal transduction system that integrates the control of photosynthesis, carbon dioxide assimilation, and nitrogen fixation. Proc Natl Acad Sci U S A 93, 14515-14520.
Kaplan, A., Schwarz, R., Lieman-Hurwitz, J. \& Reinhold, L. (1991). Physiological and molecular aspects of the inorganic carbonconcentrating mechanism in cyanobacteria. Plant Physiol 97, 851-855.

Karlsson, J., Clarke, A. K., Chen, Z-Y., Hugghins, S. Y., Park, Y.-I., Husic, H. D., Moroney, J. V. \& Samuelsson, G. (1998). A novel $\alpha-$ type carbonic anhydrase associated with the thylakoid membrane in Chlamydomonas reinhardtii is required for growth at ambient $\mathrm{CO}_{2}$. EMBO J 17, 1208-1216.

Kimpel, D. L., Togasaki, R. K. \& Miyachi, S. (1983). Carbonic anhydrase in Chlamydomonas reinhardtii. I. Localization. Plant Cell Physiol 24, 255-259.

Lindskog, S., Henderson, L. E., Kannan, K. K., Liljas, A. \& Strandberg, P. O. B. (1971). Carbonic anhydrase. In The Enzymes, vol. 5, pp. 587-665. Edited by P. D. Boyer. New York: Academic Press.

McKay, R. M. L., Gibbs, S. P. \& Espie, G. S. (1993). Effect of dissolved inorganic carbon on the expression of carboxysomes, localization of Rubisco and the mode of inorganic carbon transport in cells of the cyanobacterium Synechococcus UTEX 625. Arch Microbiol 159, 21-29.

Malamy, M. H. \& Horecker, B. L. (1964). Release of alkaline phosphatase from cells of Escherichia coli upon lysozyme sphaeroplast formation. Biochemistry 3, 172-175.

Maren, T. H. \& Sanyal, G. (1983). The activity of sulfonamides and anions against the carbonic anhydrase of animals, plants and bacteria. Annu Rev Pharmacol Toxicol 23, 439-459.

Monson, E. K., Ditta, G. S. \& Helinski, D. R. (1995). The oxygen sensor protein, FixL, of Rhizobium meliloti. J Biol Chem 270, $5243-5250$.

van Niel, C. B. (1944). The culture, general physiology, and classification of the non-sulfur purple and brown bacteria. Bacteriol Rev 8, 1-118.

Perlman, D. \& Halvorson, H. O. (1983). A putative signal peptidase recognition site and sequence in eukaryotic and prokaryotic signal peptides. J Mol Biol 167, 391-409.

Price, G. D., Coleman, J. R. \& Badger, M. R. (1992). Association of carbonic anhydrase activity with carboxysomes isolated from the cyanobacterium Synechococcus PCC7942. Plant Physiol 100, 784-793.

Qian, Y. \& Tabita, F. R. (1996). A global signal transduction system regulates aerobic and anaerobic $\mathrm{CO}_{2}$ fixation in Rhodobacter sphaeroides. J Bacteriol 178, 12-18.

Rawat, M. \& Moroney, J. V. (1995). The regulation of carbonic anhydrase and ribulose 1,5-biphosphate carboxylase/oxygenase activase by light and $\mathrm{CO}_{2}$ in Chlamydomonas reinhardtii. Plant Physiol 109, 937-944.

Smith, K. S., Jakubzick, C., Whittman, T. S. \& Ferry, J. G. (1999). Carbonic anhydrase is an ancient enzyme widespread in prokaryotes. Proc Natl Acad Sci U S A 96, 15184-15189.

Soltes-Rak, E., Mulligan, M. E. \& Coleman, J. R. (1997). Identification and characterization of a gene encoding a vertebrate-type carbonic anhydrase in cyanobacteria. J Bacteriol 179, 769-774.

Sugrue, M. F. (1996). The preclinical pharmacology of dorzolamide hydrochloride, a topical carbonic anhydrase inhibitor. $J$ Ocul Pharmacol 12, 363-376.

Tabita, F. R. (1995). The biochemistry and metabolic regulation of carbon metabolism and $\mathrm{CO}_{2}$ fixation in purple bacteria. In Anoxygenic Photosynthetic Bacteria: Advances in Photosynthesis, pp. 885-914. Edited by R. E. Blankenship, M. T. Madigan \& C. E. Bauer. Dordrecht: Kluwer.

Tai, S.-P. \& Kaplan, S. (1985). Intracellular localization of 
phospholipid transfer activity in Rhodopseudomonas sphaeroides and a possible role in membrane biogenesis. J Bacteriol 164, 181-186.

Tashian, R. E. (1989). The carbonic anhydrases: widening perspectives on their evolution, expression and function. BioEssays 10, 186-192.

Unden, G. \& Schirawski, J. (1997). The oxygen-responsive transcriptional regulator FNR of Escherichia coli: the search for signals and reactions. Mol Microbiol 25, 205-210.

Vandenberg, J. I., Carter, N. D., Bethell, H. W. L., Nogradi, A., Ridderstrale, Y., Metcalfe, J. C. \& Grace, A. A. (1996). Carbonic anhydrase and cardiac $\mathrm{pH}$ regulation. Am J Physiol 40, 1838-1846.

Wilbur, K. M. \& Anderson, N. G. (1948). Electrometric and colorimetric determination of carbonic anhydrase. J Biol Chem 176, 147-154.

Yu, J.-W., Price, G. D., Song, L. \& Badger, M. R. (1992). Isolation of a putative carboxysomal carbonic anhydrase gene from the cyanobacterium Synecochoccus PCC7942. Plant Physiol 100, 794-800.

Received 9 May 2000; revised 19 July 2000; accepted 1 August 2000. 